\title{
Fitting Simulation Evaluated on Self Body Scanned and Programmed Avatars
}

\author{
Shu-Hwa LIN ${ }^{* a}$, Rayneld JOHNSON ${ }^{b}$, Ju-Young KANG ${ }^{a}$, Didier STRICKER ${ }^{c}$, Yan CUI ${ }^{c}$ \\ aUniversity of Hawaii at Manoa, Honolulu HI, USA; \\ bayne State University, Detroit MI, USA; \\ 'DFKI, Augmented Vision, Kaiserslautern University, Germany \\ http://dx.doi.org/10.15221/13.062
}

\begin{abstract}
Avatars and virtual fitting simulations provide an opportunity for designers to view designs and fit on the body prior to construction. Additionally, computer programs now offer a selection of avatars. This study explores and evaluates a fitting simulation using a custom avatar developed through self body scanning and a pre-programmed avatar selected from 3D CAD virtual prototyping software. For the fitting simulation, a convenience sample of ten volunteers developed their own custom avatar using the Kinect 3D Body Scanning system and then selected an existing computer avatar based on their measurements from the prototyping software, Optitex. Pattern designs were then selected from the software and fitted on both avatars. Using select criteria, three design professionals assessed the fit of the designs on each avatar and compared the results. Findings indicate differences in the appearance and aesthetics of the avatars, realistic reflection of individual differences in body types and accuracy of the relationship of the garment to the body. Although the programmed avatar offers a more refined aesthetically pleasing body image, the custom self body scanned avatar provides more realistic body proportions, fabric drape and fit.
\end{abstract}

Keywords: avatars, fitting simulation, 3D body scanning, Kinect

\section{Introduction}

For more than two decades, 3D body scanning systems and computerized avatars have been developing to offer consumers new options in apparel fit and virtual try-on [1, 2, 3, 11]. Consumers can create a personalized avatar by first selecting a programmed avatar whose measurements are closest to one's own and choosing like personal features such as hair, skin color and eyes. Personalized avatars are being used in a variety of applications such as virtual try-on and the design process to facilitate visualization of garment fit. Select retailers and apparel companies offer consumers an opportunity to personalize a programmed avatar to try-on and visualize a garment prior to purchase [3]. Fit is cited as a major consumer complaint and virtual try-on is intended to increase consumer satisfaction and reduce customer returns [3, 4, 10, 11]. More recent technical advancements such as the Virtual Try On, gives additional physical simulation and an animated virtual avatar in an attempt to display garment movement and fabric drape on the body [9]. Another method to provide more realism and mirror imaging in virtual avatar representation is through 3D body scanning systems such as Kinect. Kinect, developed by Microsoft, is an affordable home device that senses motion as output [5]. Kinect employs a revolutionary technique designed for games, entertainment and fitness (Wii-Fit) [5, 6].

For the design process, computerized programmed avatars also assist a designer's visualization of a garment before production. However, if the designer is creating a garment for himself or herself, an avatar that mirrors one's own body as closely as possible could offer a more realistic visualization of a garment and increase the potential for a successful design outcome. Also, research studies suggest favorable attitudes toward the body scanning process $[4,5,8,12]$. It follows to raise the question. Does using a 3D body scanning system such as Kinect to scan oneself and create an avatar versus using a customized programmed avatar in the design process influence better visualization of fit? This exploratory study investigates attitudes toward a fitting simulation on self-body scanned and personalized programmed avatars. 


\section{Method}

\subsection{Participants}

A convenience sample of 10 designers including 9 females and 1 male voluntarily participated in this exploratory study and created two avatars using two different methods. Additionally, using select criteria, 3 design professionals voluntarily evaluated the appearance, smoothness and fit of each avatar.

\subsection{Procedure}

For the fitting simulation, participants were directed to create two personalized avatars using two different methods. For one method, participants used the Kinect system to scan their bodies and generate a custom avatar. For the other method, participants selected a programmed avatar from the 3D CAD virtual prototype software, Optitex, based on measurements closest to oneself. Continuing on the prototype software, participants then designed a variety of basic garments such as skirts, Tshirts and sleeveless straight dresses, and then virtually fit the garments on both avatars. Following the fitting simulation, three design professionals viewed, compared and evaluated each avatar. The front, side, and back views of each avatar were rated on appearance, smoothness and fit on a scale of 1-10, 1 being Unsatisfied and 10 being Satisfied.

\subsection{Instrument}

Using a closed rating scale of 1-10, 1 being Unsatisfied and 10 being Satisfied, the design professionals compared the front, side and back views of each avatar. Numerical ratings were recorded on a table for each garment design.

\section{Results}

Five of the ten tables were selected to present as examples of the evaluators' ratings including the following styles: A-line Skirt, T-shirt, Tank Top and Straight Skirt, Woman's Dress, and Sleeveless Straight Dress.

Table 1 displays the ratings for the A-line Skirt. Higher ratings for appearance, smoothness and fit were assessed for the self-scanned avatar. However, the Optitex avatar presents a more aesthetically pleasing image.

Table 1. A-line Skirt

\begin{tabular}{|c|c|c|c|c|c|c|c|c|c|}
\hline & \multirow{2}{*}{\multicolumn{2}{|c|}{$\begin{array}{l}\text { Self-scanned } \\
\text { Avatar }\end{array}$}} & \multicolumn{7}{|c|}{ Optitex Avatar } \\
\hline & & & \multicolumn{3}{|c|}{ Mean } & & & \multicolumn{2}{|c|}{ Mean } \\
\hline \multicolumn{10}{|l|}{ Appearance } \\
\hline $\mathrm{F}$ & 10 & 10 & 10 & 10 & $\mathrm{~F}$ & 8 & 8 & 9 & 8.3 \\
\hline$S$ & 9 & 10 & 10 & 9.3 & $S$ & 9 & 8 & 9 & 8.6 \\
\hline $\mathrm{B}$ & 10 & 10 & 10 & 10 & B & 8 & 8 & 9 & 8.3 \\
\hline \multicolumn{10}{|l|}{ Smoothness } \\
\hline $\mathrm{F}$ & 10 & 10 & 10 & 10 & $\mathrm{~F}$ & 8 & 8 & 9 & 8.3 \\
\hline$S$ & 10 & 10 & 10 & 10 & $S$ & 8 & 7 & 9 & 8 \\
\hline B & 10 & 10 & 10 & 10 & B & 8 & 8 & 9 & 8.3 \\
\hline \multicolumn{10}{|l|}{ Fit } \\
\hline $\mathrm{F}$ & 9 & 9 & 10 & 9.3 & $\mathrm{~F}$ & 9 & 9 & 9 & 9 \\
\hline$S$ & 9 & 10 & 10 & 9.6 & $S$ & 9 & 9 & 9 & 9 \\
\hline B & 10 & 10 & 10 & 10 & B & 9 & 9 & 9 & 9 \\
\hline
\end{tabular}

$\mathrm{F}=$ Front view, $\mathrm{S}=$ Side view, and $\mathrm{B}=$ Back view 
Evaluations for the for the Man's T-shirt are presented in Table 2. Higher ratings in appearance, smoothness and fit were assessed for the Optitex avatar. However, it was noted that the smooth wrinkle free appearance of the Optitex avatar did not accurately reflect the drape of the fabric, whereas the self-scanned avatar did reflect more realistic creases in the fabric.

Table 2. Man's T-shirt

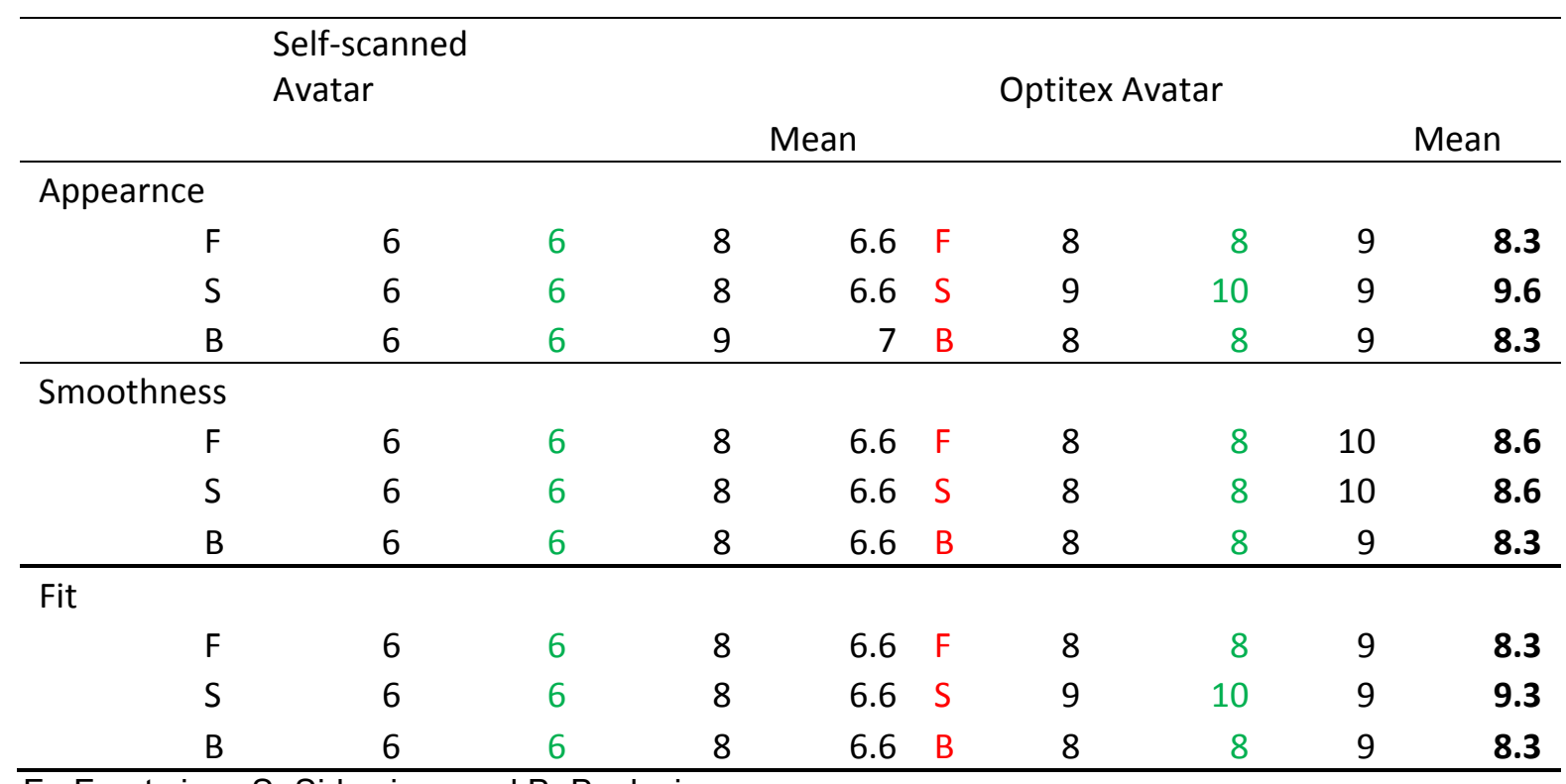

$\mathrm{F}=$ Front view, $\mathrm{S}=$ Side view, and $\mathrm{B}=\mathrm{Back}$ view

The evaluation of the Tank Top and Straight Skirt are presented in Table 3. The ratings are very close, but the scores for the Optitex avatar are slightly higher. Differences were viewed mainly in the torso and at the hem of the garments. The self-scanned Kinect avatar portrayed the drape of the lightweight fabric and relativity of the fabric to the body more accurately.

Table 3. Tank Top and Straight Skirt

\begin{tabular}{|c|c|c|c|c|c|c|c|c|c|}
\hline & \multirow{2}{*}{\multicolumn{2}{|c|}{$\begin{array}{l}\text { Self-scanned } \\
\text { Avatar }\end{array}$}} & & & & \multicolumn{4}{|c|}{$\begin{array}{l}\text { Optitex } \\
\text { Avatar }\end{array}$} \\
\hline & & & \multicolumn{3}{|c|}{ Mean } & & & \multicolumn{2}{|c|}{ Mean } \\
\hline \multicolumn{10}{|l|}{ Appearance } \\
\hline $\mathrm{F}$ & 9 & 10 & 9 & 9.3 & $\mathrm{~F}$ & 9 & 10 & 9 & 9.6 \\
\hline$S$ & 9 & 10 & 9 & 9.3 & $S$ & 10 & 10 & 9 & 9.6 \\
\hline $\mathrm{B}$ & 9 & 8 & 9 & 8.6 & B & 10 & 10 & 9 & 9.6 \\
\hline \multicolumn{10}{|c|}{ Smoothness } \\
\hline $\mathrm{F}$ & 10 & 10 & 9 & 9.6 & $\mathrm{~F}$ & 10 & 10 & 9 & 9.6 \\
\hline$S$ & 10 & 10 & 9 & 9.3 & $S$ & 10 & 10 & 9 & 9.6 \\
\hline $\mathrm{B}$ & 9 & 9 & 9 & 9 & B & 10 & 10 & 9 & 9.6 \\
\hline \multicolumn{10}{|l|}{ Fit } \\
\hline $\mathrm{F}$ & 10 & 10 & 9 & 9.6 & $\mathrm{~F}$ & 10 & 10 & 9 & 9.6 \\
\hline$S$ & 10 & 10 & 9 & 9.6 & $S$ & 10 & 10 & 9 & 9.6 \\
\hline B & 9 & 8 & 9 & 8.6 & B & 10 & 10 & 9 & 9.6 \\
\hline
\end{tabular}


Table 4. displays the ratings for the Woman's Dress. Slightly higher scores are indicated for the programed avatar versus the self-scanned avatar. The fitting simulation displayed good appearance, smoothness and fit in the bodice. Differences were judged in the torso and hem. More natural wrinkles were evident in the self-scanned avatar. Additionally, the appearance of the wrinkle at the hemline on the self-scanned avatar suggested potential pattern alterations.

Table 4. Woman's Dress

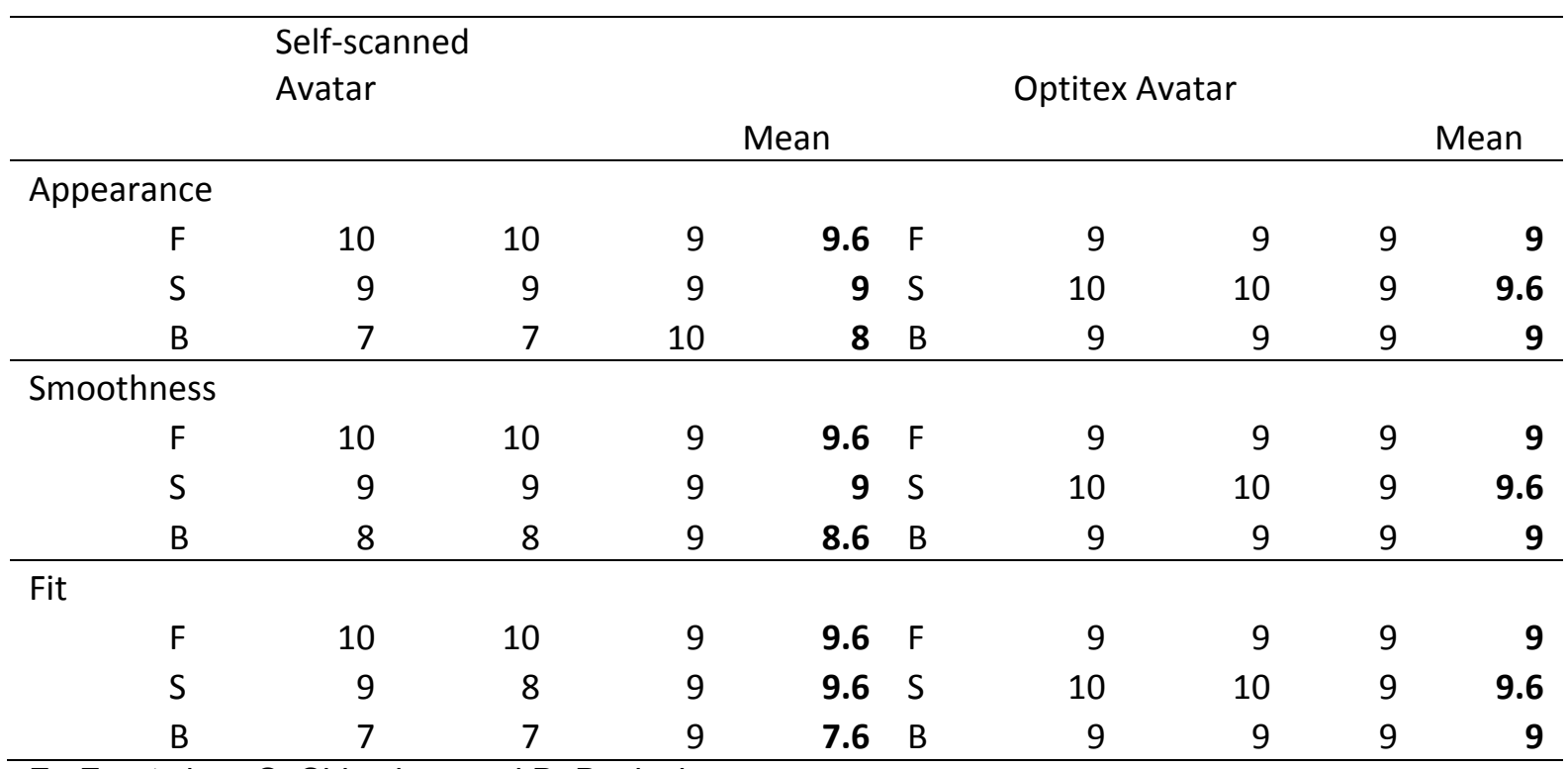

$\mathrm{F}=$ Front view, $\mathrm{S}=$ Side view, and $\mathrm{B}=$ Back view

The results of the evaluation of the Sleeveless Straight Dress fitting simulation are shown in Table 5. The comparative ratings are very close but the Optitex avatar scored slightly higher on appearance and smoothness but almost equal for fit. The self-scanned avatar portrayed more natural fabric lines.

Table 5. Sleeveless Straight Dress

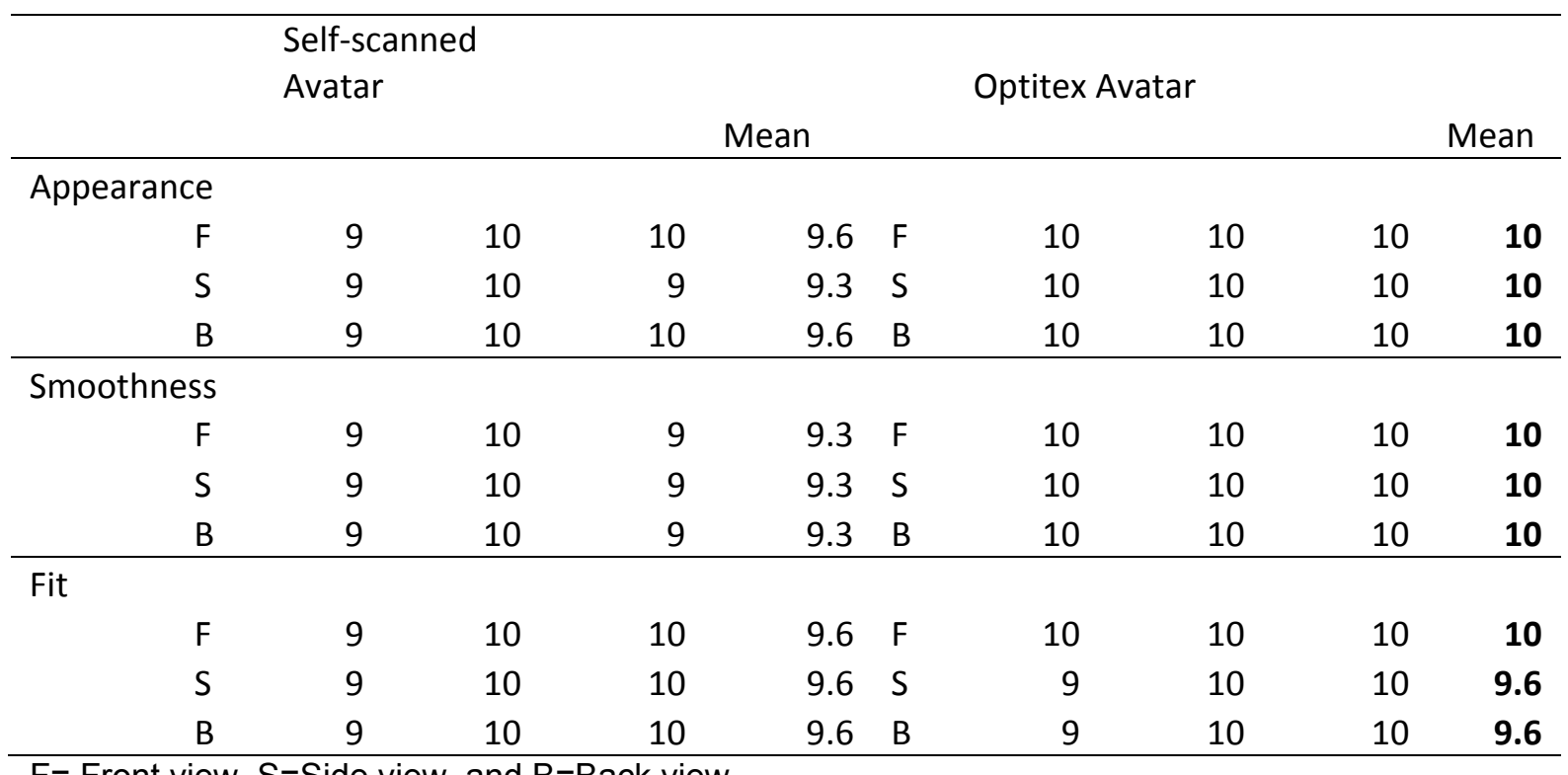

$\mathrm{F}=$ Front view, $\mathrm{S}=$ Side view, and $\mathrm{B}=$ Back view 


\section{Conclusion}

Findings indicate a low range of differences in appearance, smoothness and fit for the fitting simulations on the two avatars [7, 12, 13]. However, it was observed that the garment fabrics on the Optitex avatars were consistently smooth, stiff and close to the body. In contrast, the fabrics on the self-scanned avatars displayed more realistic fabric creases, drape and relationship of the fabric to the body. Additionally, the image of Optitex avatar is more aesthetically pleasing. The surface of the self-scanned avatar and some of the contour areas of the figure need more refinement. Also, the selfscanned avatar showed more realistic differences in body types and proportions. As affordable, 3D body scanning home systems improve and become available, consumers and designers, can look forward to improved garment fit through virtual applications $[6,7]$.

\section{References}

1. Istook, C. L. and Hwang, S., (2001): "3D body scanning systems with application to the apparel industry", Journal of Fashion Marketing and Management, Vol. 5, No. 2, pp. 120-132.

2. Jones, S. G., Schmidt, A. and Rossi, C., (2010): "3D scanning systems", Journal of New Technologies, Vol.5, No.11, pp.35-38.

3. Kim, J. and Forsythe, S., (2008): "Adoption of virtual try-on technology for online apparel shopping", Journal of Interactive Marketing, Vol. 22, No. 2, pp. 45-59.

4. Lee, Y., Damhorst, M. L., Lee, M., Kozar, J. M. and Martin, P., (2012): "Older women's fit and style concerns and their attitudes toward the use of 3D body scanning", Clothing and Textiles Research Journal, Vol. 30, No. 2, pp. 102-118.

5. Lin, S., Johnson, R., Stricker, D. and Cui, Y., (2012): "Exploratory analysis of college students' satisfaction of body scanning with Kinect", Proceedings of $3^{\text {rd }}$ International Conference on Body Scanning Technologies, Lugano, Switzerland.

6. Lin, S. and Mammel, K., (2011): "An analysis of Digital 3D body imaging technology", Proceedings of the $2^{\text {nd }}$ International Conference on 3D Body Scanning Technologies, Lugano, Switzerland, pp. 58-65.

7. Loker, S., Ashdown, S., Cowie, L. and Schoenfelder, K., (2004): "Consumer interest in commercial application of body scan data", Journal of Textile and Apparel Technology and Management, Vol. 4, No. 1, pp. 1-13.

8. Loker, S., Cowie, L., Ashdown, S., and Lewis, V. D., (2004): "Female consumers' reactions to body scanning", Clothing Textile \& Research Journal, Vol. 22, No. 4, pp. 151-160.

9. Magnenant-Thalmann, N., Kevelham, B., Volino, P., Kasap, M. and Lyard, E., (2011): "3D webbased virtual try on of physically simulated clothes", Computer-Aided Design \& Applications, Vol. 8, No. 2, pp. 163-174.

10. Nam, J. Hamiln, R., Gam, H. J., Kang, J. H., Kim, J., Kumphai, P., Starr, C. and Richards, L., (2006): "The fashion-conscious behaviours of mature female consumers", International Journal of Consumer Studies, pp. 102-108.

11. Nantel, J., (2004): "My virtual model: Virtual reality comes into fashion", Journal of Interactive Marketing, Vol. 18, No. 3, pp. 73-86.

12. Song, H. K., Ashdown, S. P., (2013): "Female apparel consumers' understanding of body size and shape: Relationship among body measurements, fit, satisfaction and body cathexis", Clothing and Textiles Research Journal, Vol. 31, No. 3, pp. 143-156.

13. Suh, K., Kim, H., and Suh, E.K., (2011): "What if your avatar looks like you? Dual-congruity perspectives for avatar use", MIS Quarterly, Vol. 35, No. 3, pp. 711-729. 